\title{
JORNALISMO E INTERNET. \\ O ESPECTRO DA REDUNDÂNCIA
}

\author{
HELDER Bastos *
}

O modelo tradicional da comunicação de massas tem sido marcado pela preponderância do emissor sobre o receptor. Os media noticiosos tradicionais - meios impressos, rádio e televisão - baseiam-se num modelo comunicacional de tipo centralizado ou «de um para muitos».

As novas tecnologias, em particular as que assentam na transmissão digital texto, áudio e vídeo através de redes telemáticas, representam uma ruptura com a centralização emissora, permitindo a emergência de um novo modelo, "de muitos para muitos», no qual as audiências se transformam em produtores para além de consumidores (Lapham, 1995). O advento do novo ambiente comunicacional, interactivo e multimediático está, portanto, a alterar o modelo que por muito tempo orientou a comunicação de massas (Manta, 1997).

A materialização do novo modelo distribuído é sobremaneira evidente na Internet, rede telemática global de estrutura e arquitectura singulares, através da qual circulam, multidireccionalmente, conteúdos gerados por uma enorme variedade de produtores, desde media estabelecidos a utilizadores comuns. Parte dos conteúdos gerados, no entanto, nem sequer passa pelos fornecedores tradicionais. Nos milhares de grupos de conversação existentes, produção e partilha de informação são consumadas de modo espontâneo e constante entre os participantes, simultaneamente consumidores e produtores, comunicando «muitos para muitos».

* Editor da redacção norte do Diário de Noticias. Docente da Escola Superior de Jornalismo do Porto. 
Mais do que proporcionarem um mero desenvolvimento de formas existentes de comunicação, as tecnologias ligadas aos novos media, como é o caso da Internet, estão a criar virtualmente um novo meio de comunicação pública. Permitido pela convergência das telecomunicações, da computação e dos media, o novo panorama mediático oferece interactividade, controlo total por parte do utilizador e comunicação em formato multimédia. «Da realidade virtual à auto-estrada da informação, a paisagem das tecnologias dos novos media é tão diversa quanto rápida na mudança. Estas novas tecnologias estão a transformar radicalmente quase todos os aspectos da maneira como comunicamos» (Pavlik, 1996: 1).

No contexto dos novos media, o mesmo medium, como assinala McQuail, pode ser utilizado simultaneamente em usos públicos e privados e em conteúdos. A longo prazo, isso tem implicações, não só para as definições de media dantes separados, mas também para as fronteiras da própria instituição dos media. A produção não necessita de estar tão concentrada em grandes organizações (o que acontece com a televisão ou com o cinema), nem ligada integralmente com a distribuição (televisão e rádio).

Os media impressos também não ficarão imunes às mudanças, à medida que a distribuição electrónica directa pelas casas se tornar uma realidade e que a organização da produção e o trabalho dos jornalistas e dos autores for computadorizada (Weaver e Wilhoit, 1986).

O desenvolvimento e potenciação da Internet, em particular nas suas vertentes de interactividade, multiplicidade e personalização informativa, vieram colocar na agenda da discussão teórica a importante questão da pertinência da função jornalística tradicional. Será que, face à propagação do novo medium, o jornalismo corre, a prazo, o risco de se tornar redundante, como alguns autores sugerem? $\mathrm{O}$ acesso directo dos utilizadores às notícias feitas à sua medida acabará por diminuir o papel crítico do jornalismo? Ou acontecerá o contrário, isto é, os utilizadores necessitarão mais do que nunca de profissionais que sirvam de referência e de guia na imensidāo informativa do ciberespaço?

\section{O espectro da redundância}

Para Jo Bardoel (1996), terá de se equacionar, antes de mais, o facto de a explosão de informação estar a criar uma crescente "pressão de comunicação" sobre a sociedade. $O$ fornecimento de informação está a expandirse, enquanto que o tempo disponível para o seu consumo se mantém mais ou menos constante. A velocidade a que a informação circula na sociedade, naquilo a que Jim Willis (1994) chamaria a era das «turbonotícias», aumenta exponencialmente. No contexto de um espaço público denso e 
empacotado em termos informativos, os jornalistas estão a encontrar dificuldades acrescidas para atraírem a atenção do público.

Segundo Bardoel, a característica mais distintiva dos novos serviços telemáticos, a interactividade, mina desde logo a posição do jornalismo. "A ênfase muda da distribuição de informação indirecta para a pesquisa directa de informação. Cada vez mais é o receptor que faz a seleç̧ão. Apesar de ser justo dizer que apenas um público limitado fará efectivamente uso de tais oportunidades interactivas, o seu significado é considerável, pois permitem acesso a fontes que os jornalistas tinham em exclusivo até agora. Serviços interactivos podem também constituir um incentivo para a crescente comunicação entre cidadãos, para a comunicação horizontal na sociedade. $O$ avanço de «media não mediados» pode exercer pressão na posição e no efeito de filtragem dos media e dos jornalistas» (Bardoel, 1996: 163). Mais ainda, acrescenta o autor, a combinação de computadores e redes fornece novas oportunidades para a comunicação em campos da vida social praticamente intocados pelos media tradicionais. Novos sectores da sociedade começam a emergir em termos de visibilidade mediática, começando a ser crescentemente mediatizados.

Todavia, o espectro da redundância do jornalismo e dos jornalistas não impede Bardoel de considerar que a profissão vai continuar a desempenhar um papel crucial na selecção e processamento de assuntos relevantes das diferentes esferas públicas. "A função do jornalismo como director do debate social será mais necessário do que nunca numa sociedade na qual a pressão da comunicação está a crescer. É importante que os jornalistas levem mais a sério esta função de intermediação do que aquilo que parecem levar no presente» (Ibid.: 167).

Para Koch (1996), os novos recursos online à disposição do cidadão comum estão em competição directa com os órgãos tradicionais e com a definição consagrada pelo tempo de notícias «públicas» e colocam a hipótese de se tornear a necessidade de um jornalista para mediação da informação. «Não preciso mais de um jornal para ler as cotações da bolsa ou as análises de negócios. Posso ultrapassar notícias em terceira ou quarta mão e obter informação primária - ou pelo menos secundária - no meu computador de casa. Não preciso mais da estória de um repórter se quiser saber a descoberta científica de um investigador. Posso ler o press release da sua universidade ou empresa na $P R$ Newswire. Posso ler online os artigos desse investigador, muitas vezes antes de serem publicados. Tenho acesso a melhor e mais informação completa do que o jornalista tradicional cuja função, em teoria, se não em prática, era a de me informar sobre o mundo que partilhamos e explicar-me as suas mudanças» (p. 20).

A natureza da própria indústria da informação mudará. Seguindo de perto a linha de Pavlikk, Koch acredita que as publicações tradicionais impressas vão desaparecer e as versões electrónicas predominar. Exemplifi- 
cando com o caso dos jornalistas ligados à área da economia, antevê que estes cada vez mais irão extrair dados em bruto à disposição de todos, na Internet e noutros meios, para utilizá-los de modo inovador. Terão de fazer isto, acrescenta Koch, porque o seu nicho tradicional (reportar conferências de imprensa e declarações oficiais) terá sido subsumido pelos sistemas de recolha de informação online.

A grande oportunidade online, escreve Fulton (1996), é permitir fornecer uma maior profundidade informativa aos utilizadores poupando-lhes simultaneamente tempo. A questão, no entanto, reside em saber se no futuro recorrerão aos jornalistas ou a outros profissionais quando necessitarem de melhores filtros de informação.

Do ponto de vista do consumidor, nota Balboni (1993), o futuro da informação é rico em termos de escolhas e de possibilidades. Para o jornalista, a perspectiva poderá ser mais problemática. «Inquestionavelmente, o processo jornalístico, no qual o conteúdo é cuidadosamente recolhido e editado, será uma diferença definitiva entre produtos genuinamente noticiosos e tudo o resto no domínio digital. Em última instância, será a integridade da recolha das notícias e dos processos de edição que distinguirão o jornalista de outros que procuram servir necessidades de informação semelhantes» (p. 49).

$\mathrm{O}$ investimento na personalização da informação levanta, por outro lado, questões atinentes ao impacto social e político desta nova tecnologia. Certos autores mostram-se apreensivos face à possibilidade de cada utilizador poder formatar a sua própria informação, isolando-se assim de pontos de vista opostos aos recolhidos por si, enfraquecendo o diálogo político e social bem como o sentido, já de si fragmentado, de comunidade. A personalização e consequente atomização é encarada como propiciadora de uma dissonância cognitiva socialmente desagregadora (Shaw, 1997; Pavlik, 1997a; Fidler, 1997; Harper, 1997; Lucky, 1995; Bok, 1995).

Para Guérin, a personalização da informação, para além de poder conduzir os leitores a uma espécie de «autismo em linha», poderá ser o prenúncio de uma transformação completa do papel da imprensa e terá um impacto significativo na função do jornalista. Na óptica do autor, assistimos «a uma perda do sentido da imprensa on line que personaliza o seu conteúdo em função das escolhas do leitor. Toda a universalidade de uma forma de imprensa (apresentação de uma realidade polimorfa e global) desaparece em proveito de uma selectividade que pode ser sinónimo de um empobrecimento absoluto do espírito. Este suporte ideal é a própria negação de uma imprensa - ela mesma idealizada e de qualquer modo já minoritária - fornecedora das chaves de uma visão global de uma realidade que não é somente virtual.

Por outro lado, a intervenção destes agentes inteligentes suprime a própria função do jornalista: escolher, hierarquizar e pôr a informação em 
perspectiva. O papel dos jornalistas e dos mediadores na valorização das informações, a realização das escolhas editoriais e a verificação do discurso, são negadas» (Guérin, 1996: 120). O processo, acrescenta, funciona por exclusão dos editores, mediadores cuja função fundamental é verificar a informação e assegurar a sua formatação.

Fidler, no entanto, considera que esta é uma matéria sujeita de algum modo a um certo empolamento, lembrando que idênticos argumentos foram utilizados com a emergência do telefone, do cinema, da rádio e da televisão. «Enquanto que aqueles que adoptam tecnologias avançadas de ciber media talvez se tornem menos dependentes das publicações de referência para as suas informação e notícias genéricas, é pouco crível que rejeitem estas formas de documentos se os princípios da mediamorfose se continuarem a aplicar. Tal como os princípios da co-evolução e da coexistência sugerem, novas formas coexistem com formas antigas em vez de as substituírem» (Fidler, 1997: 246).

\section{Declínio do gatekeeper}

Uma das funções paradigmáticas do jornalismo tradicional é a função de gatekeeper. Cabe aos jornalistas filtrar os dados em bruto, chegados às redacções através de diversos canais e diferentes fontes, para depois apresentar ao público apenas os considerados mais importantes ou pertinentes. White (1950) utilizou o conceito de gatekeeper para estudar o desenvolvimento do fluxo de notícias dentro dos canais organizativos dos órgãos de informação e para individualizar os pontos que funcionam como «cancelas», que determinam se a informação passa ou é rejeitada.

Os principais objectivos dos primeiros estudos sobre gatekeeping eram os de determinar o grau de julgamento subjectivo (pessoal e arbitrário) envolvido no processo ou analisar a natureza dos valores-notícia aplicados nos media noticiosos. Segundo McQuail (1987), o conceito de gatekeeping, apesar de a sua utilidade e capacidade para lidar com muitas diferentes situações dos media, tem uma limitação intrínseca ao implicar que as notícias chegam prontas a serem consumidas na forma de acontecimentos-estórias às «cancelas» dos media, onde são admitidas ou excluídas. "É claro que o eventual conteúdo noticioso dos media chega através de várias vias diferentes e em diferentes formas» (p. 163). A partir daí, o mesmo conteúdo é ordenado e, por vezes, construído internamente. Para McQuail, tal construção, bem como a selecção das notícias, não é subjectiva e aleatória: tem lugar largamente de acordo com esquemas de interpretação e de relevância que são as das instituições burocráticas que não são nem fontes de informação nem as que processam acontecimentos (departamentos de polícia, tribunais, departamentos governamentais, etc.). 
Na realidade, o fluxo de material para selecção «está já regulamentado e estabilizado de uma forma bastante firme: os modos, os processos e os hábitos que provocam esta regulamentação, são já uma primeira forma de selecção. Esta é, por um lado, adequada às necessidades de organizar racionalmente o trabalho e, por outro lado, é congruente com o conjunto dos valores-notícia que têm por objectivo tornar possível a parte restante da selecção dos acontecimentos» (Wolf, 1987). Os principais factores que influenciam a eventual escolha podem ser considerados sob os cabeçalhos "pessoas», «local» ou «tempo», normalmente numa ou noutra combinação (McQuail, 1987).

Historicamente, coube às elites dos media servirem de gatekeepers para uma sociedade cada vez mais diversificada. Guiados pelos seus próprios princípios de relevância das notícias, gosto e interesse público, e severamente limitados pelo espaço e tempo disponíveis, editores dos principais media sempre decidiram a quê, e em que quantidade, as suas audiências são expostas diariamente. Ora, tal como salienta Shaw, «não há nem limites de tempo nem de espaço - e em última instância gatekeepers - na Internet. $O$ ciberespaço é infinito. Qualquer um pode disseminar informação instantaneamente através do mundo inteiro» (Shaw, 1997).

O conceito de gatekeeper sugere que, de certa forma, os jornalistas são uma espécie de guardiães daquilo que chega e não chega à esfera pública, conceito que certos autores põem em causa numa era de sobrecarga informacional e de acesso directo dos leitores a volumes enormes de documentos, dados e outras fontes de informação, bem como aos próprios jornalistas.

Hoje, os utilizadores torneiam frequentemente os media noticiosos e recorrem a motores de pesquisa da Internet, como AltaVista e Yahoo, para encontrarem a informação que procuram. A era dos jornais a darem as notícias em primeira mão acabou, em especial num universo online (Lasica, 1996). Por isso, Lasica questiona se os jornalistas são ainda gatekeepers ou precisam de uma nova metáfora para o seu papel no novo meio de comunicação.

Exemplo paradigmático desta nova realidade é o caso da coluna «Drudge Report» que Matt Drudge publica e edita na Web a título individual. Drudge, que não é jornalista profissional, ficou célebre por ter préesvaziado, através do seu Web site, a "cacha» de Michael Isikoff, repórter da revista Newsweek, sobre o alegado caso sexual entre o presidente Bill Clinton e a ex-estagiária da Casa Branca Monica Lewinsky. Drugde, que pode publicar o que quiser na rede mundial sem ter de passar por uma hierarquia semelhante à existente em qualquer redacção, reportou que os editores da Newsweek, preocupados com a "natureza explosiva» do artigo original de Isikoff, haviam tomado a decisão de adiar a respectiva publicação. «Então porque foram as críticas tão intensas? Talvez porque o novo 
meio expôs uma ferida. O verdadeiro pecado foi que eles demonstraram, para todos verem, como as notícias são feitas» (Shafer, 1998).

No fundo, Drudge tornou evidente a redundância do gatekeeping tradicional quando estão em causa casos de protelamento, ou eventual encobrimento noticioso, relacionados com a natureza delicada de certas notícias. «O exemplo de Drudge mostra que qualquer pessoa que tenha uma ligação à Internet e algo de original para dizer pode chegar a uma audiência global. Pressentindo esta desintermediação nos trabalhos, os velhos media expandiram o seu perfil na Web. Em adição ao extra da Newsweek, praticamente todos os grandes diários, newsmagazine e redes de televisão acrescentaram uma página «Crise de Clinton» aos seus Web sites» (ibid.).

A intersecção do mundo online com a computação multimédia está a redefinir a própria noção de fontes produtoras de conteúdo. Graças ao facto de as barreiras financeiras e operacionais serem reduzidas, todo o consumidor na Internet é potencialmente um produtor. Em vez de se limitar a ser um espectador passivo, o utilizador da rede pode montar o seu jornal ou serviço noticioso próprio, tal como é possível constatar através da leitura de algumas páginas ou «jornais» pessoais. «No ambiente tradicional de publicação, as empresas comerciais tenderam a dominar a criação do conteúdo dos media, quer na forma de livros, jornais, revistas, rádios ou televisões. No ambiente digital, os fornecedores de conteúdo tradicionais vão continuar a desempenhar um papel, como também o farão novas formas de fornecedores de conteúdo comerciais. Mas talvez a maior quantidade de conteúdo venha a ser criada por aquilo que é tradicionalmente pensado como a audiência dos media. Nas comunicações online, toda a gente é fornecedora de conteúdo bem como membro de uma audiência» (Pavlik, 1996: 214).

Grossman (1995) fala na emergência da «democracia do teclado», na qual cidadãos individuais têm a oportunidade de se exprimirem, individualmente ou em grupo, recorrendo ao ciberespaço: «Utilizando listas computadorizadas e redes on-line para diferentes grupos de interesse, cidadãos individuais também serão capazes de enviar o seu próprio material promocional, propaganda e publicidade em todos os géneros de formatos para indivíduos, grupos e representantes da sua escolha. Haverá um contínuo fluxo de áudio, vídeo, comunicações escritas, trocas de diálogo, sondagens e votaçōes do tipo sim/não, folhetos e programas, entrevistas, discursos, apresentações e publicitações - tudo circulando no ciberespaço e instantaneamente disponível» (p. 149).

A literatura relativa ao ciberespaço, quer geral, quer académica, está repleta de referências ao seu potencial democratizador e igualitário. É dito que a comunicação lateral, cidadão-a-cidadão, de muitos-para-muitos, via Internet, em particular através dos seus grupos de discussão, pode revitalizar uma democracia baseada nos cidadãos (Gladney, 1996). Lévy, por seu 
lado, refere que a aposta tecnopolítica no ciberespaço passa por «fornecer a uma colectividade os meios para proferir um discurso plural, sem passar por representantes» (Lévy, 1997: 93).

As implicaçōes da tecnologia dos novos media interactivos representam um profundo desafio para o futuro do jornalismo e para os profissionais da informação. Pavlik acredita que os jornalistas são uma espécie ameaçada a partir do momento em que os consumidores de informação utilizam as novas tecnologias para irem directamente às fontes informativas, contornando as tradicionais fontes jornalísticas. Com o desenvolvimento da Internet e de outras redes de comunicação globais, o monopólio dos jornalistas referente à capacidade de disseminação de notícias por todo o mundo, atempadamente e para um largo número de pessoas, começa a decair (Reddick e King, 1995).

Como escreve Hume (1995), as novas tecnologias quebram o monopólio dos jornalistas, fazendo algumas das novas notícias uma colaboração não mediada entre as fontes e as audiências. Capazes de programar os seus computadores para recolherem as suas próprias notícias personalizadas, a partir de fontes mais diversificadas do que as dos próprios jornalistas, os utilizadores das redes de comunicação podem de certa forma antecipar a produção noticiosa dos jornalistas.

Acresce o facto de certos programas de computador permitirem progressivamente o tratamento e redacção automática de textos jornalísticos sem a intervenção de profissionais: «Aplicações inteligentes que automatizam a função jornalística e começam a ligar as fontes mais directamente aos consumidores de notícias podem representar o declínio do papel do jornalismo como filtro, ou gatekeeper, na interpretação da informação em sociedade e o papel crescente das forças comerciais na redacção" (Pavlik, 1996: 216). Fundindo as noções de acesso directo aos media e de software de escrita automática de notícias, Pavlik avança a hipótese de, no futuro, não haver de todo necessidade de existirem empresas jornalísticas.

Idêntica perspectiva sobre a questão tem David Bartlett, para quem o impacto das tecnologias online poderá ser sobremaneira acentuado no jornalismo: "Quando toda a gente tem acesso a imagens em directo sobre quase tudo o que está a acontecer no mundo e as telecomunicações são definidas por redes abertas em vez de fontes selectivas lineares, o papel do jornalista muda. Os jornalistas profissionais podem vir a tornar-se desnecessários quando dados em bruto fáceis de usar estão ao alcance de todos com o simples carregar de botão. O conceito familiar de um gatekeeper jornalístico pode tornar-se insignificante quando todos os consumidores têm o poder de comandarem o seu próprio filtro» (Bartlett, 1994).

Para Koch, no mundo electrónico da comunicação, os cidadãos/utilizadores tomam paulatinamente controlo dos media emergentes, definindo os padrões de desenvolvimento através dos mecanismos de procura pública. 
«Os utilizadores, não os proprietários, estão a determinar a forma do mundo online em desenvolvimento. Desde há uma década, aqueles cujos interesses vão desde a aviação à zoologia têm organizado "fóruns» e «conferências» on line, por exemplo, vergando estas novas tecnologias aos seus próprios e partilhados interesses» (Koch, 1996: 9).

Christopher Harper partilha das preocupações relativamente ao futuro do jornalista neste contexto: "Os papéis do repórter e do editor de jornal os tradicionais gatekeepers da informação - são limitados, se não eliminados de todo, na decisão de qual a informação a receber pelo utilizador» (Harper, 1997).

O contrário também é objecto de discussão. Para Shaw (1997), a maior parte das pessoas não tem nem tempo nem aptidões para encontrar, seleccionar e avaliar toda a informação encontrada na rede. Apesar de a discussão à volta da eventual eliminação de intermediários ou mediadores da informação, é improvável que a Internet torne obsoletos os repórteres e editores que servem como mediadores jornalísticos, na medida em que o novo meio assume sobretudo uma função complementar, e não de anulação, relativamente ao jornalismo tradicional; por um lado, assiste o jornalismo tradicional (jornalismo online) e, por outro lado, constitui um novo canal de difusão dos conteúdos gerados pelas empresas jornalísticas tradicionais (jornalismo digital). Poderá igualmente colocar-se a questão de saber se o fim dos jornalistas não significaria também o desaparecimento das notícias no sentido jornalístico tradicional do termo: o consumidor passaria a consumir apenas informação, dispensando a notícia enquanto matéria processada e contextualizada por profissionais preparados para o efeito.

Howard Rheingold defende que quanto mais material informativo existe no ciberespaço maior é a necessidade de haver filtros, mais são necessárias pessoas que saibam como cultivar fontes, verificar a informação e colocar a marca de legitimidade nela. «Toda a gente já tem demasiada informação, e brevemente teremos espaço para ainda mais informação. Conhecimento é informação necessária, de uma forma inteligível, na altura certa. Para isso, são necessárias pessoas, não bases de dados. O processo de encontrar conhecimento é uma tarefa social, não uma tarefa técnica, especialmente na Net» (Rheingold, 1995).

Embora, como salienta Singer (1998), não tenham sido ainda publicados estudos abundantes sobre a questão do gatekeeping no novo meio, existem algumas evidências de que os próprios jornalistas vêem esta função como adaptativa e evolutiva em vez de ameaçada de extinção. Reportando-se ao contexto das redacções norte-americanas, a autora refere um estudo segundo o qual os profissionais estão a mudar a sua definição de gatekeeping para incorporarem noções como controlo de qualidade e «sense-making». Em particular, vêem o seu papel de intéxpretes credíveis de um volume sem precedentes de informação disponível como fundamental 
para o seu valor profissional e mesmo para a sua própria sobrevivência no ambiente dos novos media. Singer salienta ainda o facto de, apesar de as provas ainda não serem suficientes, haver indicações de que os utilizadores on line - apesar das muito publicitadas afirmaçōes de que estes procuram precisamente libertar-se do controlo dos media sobre a informação - podem antes estar à procura de gatekeepers de alguma espécie.

Agostini também não acredita naquilo a que chama o enterro de jornais e de jornalistas, defendendo que, independentemente das técnicas, será sempre necessário haver profissionais para verificar as notícias. Lembrando que na história da comunicação jamais uma inovação provocou a eliminação das tecnologias anteriores, o autor frisa que o que desapareceram foram modos de produção e os seus instrumentos. "O jornalismo multimédia tomará portanto o seu lugar ao lado dos jornalismos tradicionais. O jornalismo do futuro será obra de cada media propondo a sua informação diferenciada. Em suma, é tempo de renunciar a essa entidade quase mitológica que chamamos jornalismo e admitir a existência de jornalismos diferenciados em função dos públicos, dos conteúdos, das formas, dos modos de produção, de difusão e de consumo da informação" (Agostini, 1997: 26). A continuidade lógica desta hipótese poderá concretizar-se na diferenciação e especialização dos perfis e das competências jornalísticas. No futuro, poderão existir jornalistas especializados em sistemas informáticos, em sistemas documentais, jornalistas editores, jornalistas visuais e jornalistas infográficos, entre outros (Pépin, 1994).

Para Giussani (1997), a Internet não é um fenómeno de substituição mas um canal de comunicação suplementar, pelo que os jornalistas têm um papel essencial a jogar na sociedade interactiva de amanhã.

Caminha-se a passos largos para um ambiente informacional global onde todos serão fornecedores de informação bem como consumidores. «O desafio está em criar comunidades electrónicas que casam informação e comunicações - criando assim um meio interactivo e participativo. Este aspecto de comunidade é crucial - é a alma do novo meio" (Gilder, 1994; citando Steven Case). No entanto, a criaçāo deste tipo de comunidades electrónicas encontra certos obstáculos, pois cada utilizador pode construir o seu pacote de informaçāo a partir da massa informativa online, tornando mais difícil o cimentar, por parte dos jornais, de um conhecimento comum entre as diversas comunidades virtuais.

\section{Conclusão}

Michael Schudson começa o seu mais recente livro, The Power of News, convidando os leitores a imaginarem um mundo onde toda a gente pode distribuir informação a toda gente através de um computador. Onde qual- 
quer pessoa pode ser o seu próprio jornalista. Schudson sugere que, num mundo destes, as pessoas depressa se sentiriam desorientadas face às complexas tarefas de escolher fontes legítimas e navegar num mar infindável de informação.

Num mundo imaginário destes, que, afinal, vemos materializar-se paulatinamente com a expansão da Internet, a necessidade de encontrar fontes fiáveis, relativamente imparciais e de confiança, parece aumentar na proporção directa do crescimento exponencial da oferta informativa. Donde, o jornalismo terá todas as condições para ser reinventado (Singer, 1998) em vez de, como proclamam alguns, ser gradualmente eliminado.

À prospectiva mais pessimista, porventura baseada mais em projecções demasiado distantes no tempo do que em sólidos indicadores do presente, poderá contrapor-se a questão de saber se certas aptidões próprias desenvolvidas pelo jornalista não se afirmarão como cruciais. As capacidades de selecção, síntese, hierarquização, enquadramento e mesmo de personalização da notícia poderão ser insubstituíveis no ciberespaço, onde fenómenos como o da sobre informação se vêem exponencialmente agravados.

Acresce que a experiência do jornalista na relação com fontes de informação, se bem que não isenta de escolhos ou vícios, poderá igualmente continuar a constituir uma mais-valia. $O$ facto de, com o novo meio, o utilizador poder dispensar a intermediação jornalística, entrando em contacto directo com as fontes, não garante, à partida, a totalidade e a fiabilidade da informação recolhida.

Se, retomando o conceito de mediamorfose de Roger Fidler, aplicarmos ao jornalismo os princípios da co-evolução e coexistência, que têm presidido à própria evolução dos media, teremos que as novas formas de jornalismo online não substituirão as tradicionais: ambas tenderão a coexistir, moldando-se e transformando-se, mutua e interactivamente, ao longo do tempo.

Não obstante, convirá não perder de vista, em termos de acompanhamento teórico, determinados aspectos que tornam única a experiência evolutiva da Internet. Trata-se de um novo meio que, para além de acolher todos os media tradicionais, conferindo-lhes novas roupagens e diferentes horizontes, se expande de forma sem precedentes no atinente a ritmo, escala, controlo e modalidades comunicacionais.

Se há uma conclusão genérica a tirar desta problemática é a de que, apesar de se antever um significativo impacto do novo meio no jornalismo, será ainda prematuro produzir asserçōes definitivas, quer sobre a forma como os jornalistas serão afectados no seu ofício, quer sobre o modo como os leitores/utilizadores se posicionarão face aos jornalismos tradicional e online.

A rápida evolução do novo meio, o seu actual estádio de desenvolvimento e a relativa imprevisibilidade das suas aplicações, nomeadamente 
no que ao jornalismo concerne, dificilmente autorizam asserções definitivas sobre questões fulcrais como a de saber se o jornalista se tornará redundante ou se o seu papel como gatekeeper sairá diminuído.

\section{REFERÊNCIAS BIBLIOGRÁFICAS}

AgostinI, Angelo. (1997) - «Le Journalisme au Defi d'Internet». Le Monde Diplomatique, Outubro, pp. 26-27.

BaLbonI, Philip S. (1993) - «Memo To: All Journalists Re: The New Information Industry». Columbia Journalism Review, Julho/Agosto, pp. 49-50.

Bardoel, Jo. (1996) - «Journalism Redundant?». In New Media New Joumalism, EJTA. Reports, Angelo Agostini (ed.), pp. 159-174.

BARTLETT, David. (1994) - «The Soul of a News Machine: Electronic Journalism in the TwentyFirst Century». Federal Communications Law Joumal, Vol. 47, N. 1 , Outubro, <http://www.law.indiana.edu/fclj/v47/no1/bartlett.html> (17.09.97).

BoK, Sissela. (1995) - «News in the Next Century: What Role for Values?». The Radio and Television News Directors Fundation, <http://www.rtndf.org/rtndf/new/bok.htm> (26.04.97).

FIDLER, Roger. (1997) - Mediamorphosis: Understanding New Media: Joumalism and Communications for a New Century. Thousand Oaks, CA: Pine Forge Press.

FulToN, Katherine. (1996) - «A Tour of Our Uncertain Future». Columbia Joumalism Review, Março/Abril, pp.19-26.

GILDER, George. (1994)-Life After Television. The Coming Transformation of Media and American Life. Norton \& Company.

Giussani, Bruno. (1997) - "Révolution dans l'Information». Le Monde Diplomatique, Outubro, pp. 26-27.

GLADNEX, George Albert. (1996) - «Some Enduring Issues of Cyberspace Technology: A Medium Theory Perspective». The New Jersey Joumal of Communication, Volume 4, Número 2, Outono, pp. 110-126.

GuERIN, Serge. (1996) - La Cyberpresse. Paris: Hermès.

HARPER, Christopher. (1997) - "The Daily Me». American Joumalism Review Newslink, Abril, <http:/www.newslink.org/ajrdailyme.html> (08.04.97).

Hume, Ellen. (1995) - «Tabloids, Talk Radio, and the Future of News: Technology's Impact on Journalism». The Annenberg Washington Program in Communications Policy Studies of Northwestern University, Washington, D.C., <http:/www.annenberg.nwu.edu/pubs/ tabloids/> (24.07.97).

KocH, Tom. (1996) - The Message is the Medium: Online All the Time for Everyone. Westport, CT: Praeger.

LAPHAM, Christine. (1995) - «The Evolution of the Newspaper of the Future». Computer-Mediated Communication Magazine, Junho, <http://sunsite.unc.edu/cmc/mag/1995/jul/lapham. $\underline{\mathrm{html}}>$ (09.04.97). 
LASICA, J. D. (1996) - «Net Gain - Joumalism's challenges in an interactive era». American Journalism Review Newslink, Novembro, <http://www.newslink.org/ajrwww.html> (11.05.97).

LEvvy, Pierre. (1997) - A Inteligência Colectiva: Para uma Antropologia do Ciberespaço. Colecçāo Epistemologia e Sociedade. Lisboa: Instituto Piaget.

LUCKY, Robert W.. (1995) - «News of the Future». Radio and Television News Directors Fundation, <http:/www.rtndf.org/rtndf/new/lucky.htm> (26.04.97)

MaNTA, André. (1997) - «Guia do Jornalismo na Internet». Cyberpesquisa, Outubro, <http:// www.facom.ufba.br/pesq/cyber/manta/Guia/index.html> (25.02.98).

Mcoual, Denis. (1987)-Mass Communication Theory: an Introduction. Second Edition. London: Sage Publications.

PAvLIK, John V.. (1997a) - "The Future of Online Journalism: A Guide to Who's Doing What». Columbia Joumalism Review, Julho/Agosto, <http:/www.cjr.org/html/97-07-08-online. html> (10.11.97).

Pavlik, John V.. (1996) - New Media Technologies and the Information Highway. Allyn \& Bacon.

PÉPIN, Patrick. (1994) - «Journalisme en 2010. Nouvelles technologies et nouveaux métiers dans la presse écrite». Cahiers de l'Ecole Supérieure de Journalisme de Lille, n. ${ }^{\circ} 6$.

REDDICK, Randy, e KING, Elliot. (1995) - The Online Joumalist: Using the Internet and Other Electronic Resources. Fort Worth, TX: Harcourt Brace:

RHEINGold, Howard. (1996) - A Comunidade Virtual. Lisboa: Gradiva.

Schudson, Michael. (1995) - The Power of News. Cambridge, MA: Harvard University Press.

SHAW, David. (1997) - "The media.com-Revolution in Cyberspace». Los Angeles Times, Special Reports, 15-19 de Junho, <http://www.latimes.com.media/> (27.07.97).

SINGER, Jane B..(1998) - «Online Journalists: Foundations for Research into Their Changing Roles». The Joumal of Computer-Mediated Communication, Vol. 4, No. 1, Setembro, $<$ http://www.ascusc.org/jcm c/vol4/issue 1/singer.html $>$ (26.10.99).

WEAVER, D., e WilHorT, C. G. (1986) - The American Joumalist. Bloomington: University of Indiana Press.

WhITE, D. M. (1950) - "The Gatekeeper: a Case Study in the Selection of News». Journalism Quartely, vol. 27, n. ${ }^{\circ}$, pp. 383-390.

WILLIS, Jim. (1994) - The Age of Multimedia and Turbonews. Westport, CT: Praeger.

Wolf, Mauro. (1987) - Teorias da Comunicaçāo. Lisboa: Editorial Presença. 